\title{
ARTIGOS
}

\section{O NOVO (VELHO) PARADIGMA EDUCACIONAL PARA O SÉCULO XXI}

RAFAEL RODRIGO MUELLER

\section{RESUMO}

O principal objetivo desta pesquisa é analisar o paradoxo existente na relação entre trabalho e educação a partir dos documentos referentes ao Programa para Avaliação Internacional das Competências dos Adultos - Paica -, da Organização para a Cooperação e Desenvolvimento Econômico - OCDE. Pretendemos demonstrar como, historicamente, os organismos multilaterais vêm se utilizando de velhas "ferramentas" (programas e/ou propostas pedagógicas) para solucionar novos "problemas" (formação profissional). Nossa tese é que a educação de forma geral foi sendo historicamente transformada e minimizada a um conjunto de aptidões e competências necessárias exclusivamente à obtenção de um posto de trabalho e que, consequentemente, vem perdendo sua função primordial em termos de formação humana.

PROGRAMA PARA AVALIAÇÃO INTERNACIONAL DAS COMPETÊNCIAS DOS ADULTOS - PAICA • ORGANIZAÇÃO PARA A COOPERAÇÃO E DESENVOLVIMENTO ECONÔMICO - OCDE • TRABALHO • EDUCAÇÃO

\section{THE NEW (OLD) EDUCATIONAL PARADIGM FOR THE 21ST CENTURY}

\section{ABSTRACT}

The main objective of this study is to analyze the paradox found in the relationship between work and education based on the documents of the Programa para a Avaliação Internacional das Competências dos Adultos [Programme for the International Assessment of Adult Competencies] - PAICA - of the Organization for Economic Co-Operation and Development-OECD. We intend to demonstrate how, historically, the multilateral organizations have been using old "tools" (programs and/or pedagogical proposals) to solve new "problems" (vocational training).

Our thesis is that education has been, in general, historically transformed and minimized into a set of aptitudes and skills focused only on getting a job and, consequently, has lost its primary function in terms of human development. 


\section{LE NOUVEAU (VIEUX) PARADIGME ÉDUCATIF POUR LE XXI SIĖCLE}

RÉSUMÉ

L'objectif principal de cette recherche est d'analyser le paradoxe présent dans les relations entre travail et éducation, à partir des documents relatifs au Programa para a Avaliação Internacional das Competências dos Adultos [Programme pour l'Évaluation Internationale des Compétences des Adultes] - PAICA -, de l'Organisation pour la Coopération et le Développement Économique - OCDE. Nous souhaitons montrer comment, historiquement, les organismes multilatéraux utilisent de vieux "outils» (programmes et/ou propositions pédagogiques) pour résoudre de nouveaux "problèmes" (formation professionnelle). Nous soutenons la thèse que l'éducation en général s'est historiquement transformée et réduite en un ensemble d'aptitudes et de compétences qui ne sont nécessaires qu'à l'obtention d'un emploi et que, par conséquent, elle est en train de perdre sa fonction primordiale de formation humaine.

PROGRAMA PARA A AVALIAÇÃO INTERNACIONAL DAS COMPETÊNCIAS DOS ADULTOS - PAICA • ORGANIZAÇÃO PARA A COOPERAÇÃO E DESENVOLVIMENTO ECONÔMICO - OCDE • TRAVAIL • ÉDUCATION

\section{EL NUEVO (VIEJO) PARADIGMA EDUCACIONAL PARA EL SIGLO XXI}

RESUMEN

El principal objetivo de la presente investigación es analizar la paradoja que existe en la relación entre trabajo y educación a partir de los documentos relativos al Programa para a Avaliação Internacional das Competências dos Adultos [Programa para la Evaluación Internacional de las Competencias de los Adultos]Paica -, de la Organización para la Cooperación y el Desarrollo Económico-OCDE. Pretendemos demonstrar cómo, históricamente, los organismos multilaterales vienen utilizando viejas "herramientas" (programas y/o propuestas pedagógicas) para solucionar nuevos "problemas" (formación profesional). Nuestra tesis plantea que la educación de forma general se fue transformando históricamente y se convirtió en un conjunto de aptitudes y competencias necesarias tan solo para obtener un puesto de trabajo y que, por ello, viene perdiendo su función primordial en lo que concierne a la formación humana. 
- STA PESQUISA PROPÕE-SE A REFLETIR SOBRE O PARADOXO EXISTENTE NA RELAÇÃO ENTRE trabalho e educação a partir dos documentos oficiais da Organização para a Cooperação e Desenvolvimento Econômico - OCDE -, particularmente aqueles referentes ao Programa para a Avaliação Internacional das Competências dos Adultos - Paica. Trata-se de um programa que tem servido como "fio condutor" do referido organismo multilateral para avaliar, desde 2011, em 33 países membros e parceiros, as políticas públicas para a educação em termos de competências necessárias para o trabalho e emprego, especificamente direcionadas para a educação de jovens e adultos. A referida avaliação contempla quatro categorias de competências genéricas profissionais: competências cognitivas, interação e aptidões sociais, capacidades físicas e aptidões de aprendizagem.

Diante dessa proposição da OCDE, despertou-nos o interesse em pesquisar, para além da aparência fenomênica, os condicionantes históricos e socioeconômicos do programa proposto pelo referido organismo multilateral, que historicamente, assim como outras organizações internacionais (Banco Mundial, Fundo Monetário Internacional - FMI -, Organização das Nações Unidas para a Educação, a Ciência e a Cultura - Unesco -, etc. ), vem assumindo uma função de regulador transnacional das políticas públicas para a educação de seus países membros, bem como para os países ditos "em desenvolvimento".

As evidências empíricas corroboradas por avaliações criteriosas realizadas por pesquisadores e cientistas sociais brasileiros (MARI; 
GRADE, 2011; MORGADO; LARA, 2011; RODRIGUES, 2009; SHIROMA, 2009, dentre outros) revelam que essas propostas educacionais, apresentadas por organismos de cooperação internacional aos países da periferia do sistema mundial, estão afinadas com o modelo de educação vigente nos países do capitalismo central, um modelo que coloca a educação como um instrumento que tem no mercado e na ideologia do desenvolvimento o seu foco central de interesse, retomando velhas teorias desenvolvimentistas, tais como a teoria do capital humano (SCHULTZ, 1971). A lógica que permeia tanto o debate quanto os documentos aqui analisados é de uma educação que instrumentaliza o indivíduo, atual e futuro trabalhador, para uma atuação mais pragmática no mercado de trabalho, possibilitando a ampliação dos níveis de produtividade e, consequentemente, de valorização do valor.

Assim sendo, entendemos que a educação vem sendo historicamente transformada e minimizada a um conjunto de aptidões e competências necessárias exclusivamente à obtenção de um posto de trabalho e que, mediante o aprofundamento das crises econômicas nos países pertencentes à OCDE, principalmente a partir de 2008, a educação vem perdendo historicamente sua função humanística em termos de formação integral e omnilateral do ser humano (MANACORDA, 2007).

Isso se estabelece, a nosso ver, por conta do paradoxo presente na relação entre trabalho e educação identificada no referido programa da OCDE: ao se utilizar de velhas "ferramentas" (programas e /ou propostas pedagógicas) para solucionar novos "problemas” (formação profissional), os organismos multilaterais, e consequente os países que seguem seu receituário para a educação, centram sua atenção em um tecnicismo exacerbado pela noção de competências, conceito-fetiche que orienta e transpassa os currículos a partir de uma lógica instrumental. Essa situação, a busca no "velho" tecnicismo, enquanto um meio para a resolução de "novos” problemas relacionados à qualificação profissional, pode ser um indicativo do fato da educação não ter criado maiores expectativas de ampliação do número de empregos ao redor do mundo. A estreita capacidade de transformação social providenciada por uma educação limitada a um "treinamento" ou "qualificação" dentro e fora da empresa, pode acirrar as crises do capital por não potencializar as capacidades intelectuais dos atuais e futuros trabalhadores em termos de possibilidades de perpetuação dos níveis de extração de mais valor. Nesse sentido, o Paica-OCDE - uma "inovação" educativa prevista em um novo método/instrumento de análise e mensuração, concebido com o intuito de medir o valor econômico da educação centrada ainda na lógica de capital humano - revela-se objetivamente como um rearranjo de antigas fórmulas e métodos voltados à qualificação profissional dentro e fora do ambiente de trabalho. 
Para verificarmos objetivamente os elementos históricos que constituem o paradoxo e a crítica a tal concepção e instrumentalização da educação, pretendemos estabelecer um nexo conceitual entre aparentemente diferentes componentes da educação dos séculos XX e XXI. A relação histórica entre propostas metodológicas e ideológicas acerca dos objetivos da educação, em termos de atendimento às demandas do mercado de trabalho e de constituição de um sujeito neoliberal autogestionado (LAVAL; DARDOT, 2016; BRÖCKLING, 2016), enquanto síntese mais refinada da teoria do capital humano, pode ser evidenciada: em sua protoforma, a partir da década de 1940, pelo método Training Within Industry - TWI -, elemento estruturante de propostas de ensino profissional no Brasil desde o final da década de 1950 até os dias atuais (SISTEMA NACIONAL DE APRENDIZAGEM INDUSTRIAL - SENAI, 2012), como dimensão instrumental do toyotismo (HUTZINGER, 2005); no relatório Faure publicado em 1973 e no relatório Delors de meados da década de 1990; e recentemente no Paica-OCDE de 2011.

A presente análise estrutura os elementos de nosso artigo, que, por fim, traz indícios de uma racionalidade aparentemente nova para educação no século XXI, em que elementos históricos voltados à instrumentalização do processo educacional se fazem presentes nas propostas de educação de organismos multilaterais, aqui representados pela OCDE, sob a lógica de constituição de sujeitos trabalhadores neoliberais (LAVAL; DARDOT, 2016) e, consequentemente, unilaterais em termos de formação humana.

\section{CHARLES R. ALLEN, O TRAINING WITHIN INDUSTRY E OS RELATÓRIOS DA UNESCO}

Para compreendermos os elementos históricos presentes na relação entre trabalho e educação nos séculos XX e XXI, é necessário que iniciemos o nosso percurso pelas propostas de instrução e ensino profissional de Charles R. Allen, supervisor de formação de professores em Massachusetts, EUA, considerado o pai do método TWI e figura-chave no desenvolvimento da educação profissional americana no início do século XX. Em 1919, Charles R. Allen escreve a obra The instructor, the man and the job, onde o autor estabelece paralelos entre dois ambientes distintos na sociedade, mas que historicamente foram se homogeneizando: a escola e a empresa. Isso verifica-se no decorrer da obra pelas constantes menções à identificação a partir de objetivos-fim presentes entre elementos como: o instrutor/professor, o trabalhador/aluno, assim como a instrução/treinamento e o ensino. De forma que tanto Allen quanto os autores e seguidores de suas ideias ligam o treinamento em uma determinada função necessária em uma empresa ao ensino escolar, ou seja, a instrução para o melhor desempenho profissional seria 
similar à educação desenvolvida na escola, assim como a ação do instrutor no ambiente de trabalho se assemelharia à do professor em sala de aula. Allen (1919, p. 5) se refere ao instrutor como um "professor, como se ele [o instrutor] fosse um professor 'regular' em uma escola” (tradução nossa).

Ainda segundo o autor, “o ensino está, portanto, sempre acontecendo em qualquer empresa"3 (tradução nossa) (ALLEN, 1919, p. 5). Nesse caso, o ensino é identificado como sendo a instrução ou o treinamento, que são tarefas meramente reprodutoras das ações transferidas pelo instrutor ao trabalhador. Para Allen (1919), os instrutores geralmente não se consideram professores, mas o são, pois ambos exercem o mesmo trabalho. Ao homogeneizar tanto as figuras do instrutor e do professor como as da educação e da instrução, Allen contribui significativamente para o que Laval (2004, p. xix) identificou, a partir da década de 1980, como sendo o processo em que "a escola que se delineia parece cada vez mais com uma empresa”. De acordo com Mueller (2013, p. 741):

\begin{abstract}
A metodologia do TWI teve como base os métodos de treinamento de Charles Allen, em 1919, desenvolvidos a princípio para a indústria naval americana durante a Primeira Guerra Mundial. Desses métodos, chamados de os "quatro passos de Allen", surgiram os "Programas J": instrução de trabalho (job instruction, JI); métodos de trabalho (job methods, JM); relações de trabalho (job relations, R); e o desenvolvimento de programa (program development).
\end{abstract}

Nesse sentido, encontramos na proposta de Allen a protoforma do que se difundiu amplamente, em especial a partir da década de 1990, como o princípio do "aprender a fazer", um dos pilares da educação do século XXI, conforme Delors et al. (2003). A proposta dos “quatro passos”, desenvolvida por Allen, atuava diretamente sobre a tríade: instrutor, trabalhador e o trabalho em si. Allen $(1919$, p. 3) reafirma a importância dos três elementos a partir de uma lógica produtiva utilitarista:

[...] o instrutor, porque é através de instrução eficaz que podemos assegurar eficiência em treinamento. O homem, porque, quando corretamente treinado, ele faz o melhor trabalho. O serviço, porque eficiência produtiva vem de homens bem treinados. ${ }^{4}$ (tradução nossa)

Esse mesmo pragmatismo presente no método dos "quatro passos” de Allen é apropriado por seus colegas Channing Rice Dooley e Walter Dietz, juntamente com Mike Kane e William Conover, durante a Segunda Guerra Mundial, para conceberem naquele período o TWI. Segundo estudo do Senai (2012), esse método foi elaborado para desenvolver três capacidades - observar, ouvir e fazer -, fragmentando as as if he were a 'regular' teacher in a school". 3 No original: "teaching is therefore always going on in any shop".

4 No original: "the instructor because it is through effective instruction that we can secure efficiency in training. The man, because when properly trained he does the best work. The job, because production efficiency comes from well instructed men doing good jobs". 
fases de execução de uma tarefa, facilitando o rápido treinamento. O TWI se estrutura a partir da proposta dos "três J" acima citada acrescida dos "quatro passos" de Allen.

Na década de 1940, o TWI irá acelerar exponencialmente a produtividade necessária à indústria bélica que irá abastecer os EUA em sua participação na Segunda Guerra Mundial, conforme relato do Senai (2012), no qual a construção de um navio que inicialmente levava duas semanas, após a inserção do TWI no processo produtivo, reduziu-se para quatro dias, 15 horas e 30 minutos. O próprio Senai afirma que o método em questão foi amplamente utilizado no Brasil, para auxiliar em seu processo de industrialização, a partir de 1950. Para além de sua natureza industrial, o TWI se mostra um método de forte inclinação técnico-operacional que irá justificar e legitimar a ideia de "ensinar para o trabalho" ou, mais propriamente, “aprender a fazer”, como um preceito que deva ser perseguido pela escola e consequentemente pelos professores. Hutzinger (2005) e Mueller (2013) indicam que o TWI fora incorporado como um elemento do sistema Toyota de produção, sendo esse o paradigma produtivo que historicamente se torna hegemônico no ambiente organizacional a partir da década de 1980.

Para demonstrarmos de forma mais objetiva a relação entre os “quatro passos” de Charles Allen, o TWI e o sistema Toyota de produção, estruturamos uma síntese desses três elementos a partir do quadro a seguir.

\section{QUADRO 1}

COMPARAÇÃO ENTRE OS "QUATRO PASSOS”, O TWI E O KAIZEN

\begin{tabular}{|c|c|c|c|c|c|}
\hline \multirow{2}{*}{ PASSO } & \multirow{2}{*}{$\begin{array}{c}\text { CHARLES } \\
\text { ALLEN }\end{array}$} & $\begin{array}{c}\text { TNSTRUÇÃo } \\
\text { DE TRABALHO }\end{array}$ & $\begin{array}{c}\text { MÉTODOS DE } \\
\text { TRABALHO }\end{array}$ & $\begin{array}{c}\text { RELAÇÕES DE } \\
\text { TRABALHO }\end{array}$ & \multirow{2}{*}{ KAIZEN } \\
\cline { 3 - 5 } & Preparação & Prepare & Pare & $\begin{array}{c}\text { Entenda os } \\
\text { fatos }\end{array}$ & $\begin{array}{c}\text { Observe e marque o } \\
\text { tempo do processo atual }\end{array}$ \\
\hline 2 & Apresentação & Apresente & Questione & $\begin{array}{c}\text { Compare e } \\
\text { decida }\end{array}$ & Analise o processo atual \\
\hline 3 & Aplicação & Tente & Desenvolva & $\begin{array}{c}\text { Tome uma } \\
\text { ação }\end{array}$ & $\begin{array}{c}\text { Implemente e teste um } \\
\text { novo processo }\end{array}$ \\
\hline 4 & Teste & Acompanhe & Aplique & $\begin{array}{c}\text { Verifique os } \\
\text { resultados }\end{array}$ & $\begin{array}{c}\text { Documente o novo } \\
\text { padrão }\end{array}$ \\
\hline
\end{tabular}

Fonte: Hutzinger (2005).

Enquanto uma tecnologia gerencial (MUELLER, 2013) concebida para atuar sobre a força de trabalho, tanto de forma objetiva - o processo de trabalho -, quanto subjetiva - o comportamento e as atitudes do trabalhador frente o trabalho -, o TWI aliado a um dos pilares do sistema toyotista, o kaizen, estabelece-se no ambiente produtivo semelhante a uma proposta pedagógica escolar. Destarte, verifica-se que, a partir da década de 1990, a filosofia organizacional toyotista manifesta-se no 
ambiente escolar sob várias formas: desde a pedagogia de projetos, o ideário da "qualidade total" no ensino e, principalmente, como meio de articular, de forma mais objetiva, a estrutura curricular de ensino às demandas do mercado de trabalho em termos de qualificação profissional para o atual e futuro trabalhador. O que se espera da educação e da escola a partir dessa constatação, enquanto objetivo-fim, é a formação/preparação de um atual e futuro aluno-trabalhador "toyotizado". Para além disso, o kaizen, enquanto um dos pilares do toyotismo, significa o processo de "melhoria contínua” presente e necessário para o aprimoramento da produtividade, assim como, e em direta concomitância, temos o preceito de longlife education: a educação ao longo da vida necessária ao atual e futuro trabalhador para que se mantenha empregável e constantemente produtivo e assimilável pelo mercado de trabalho.

Conforme Werthein (2000, p. 15),

\begin{abstract}
O postulado de educação para todos ao longo da vida (lifelong education) defendido pelo Relatório daria origem a sucessivos estudos e, aos poucos, ele foi sendo adotado pelos países, como também se faria presente nos principais documentos de orientação da UNESCO (Relatório Jacques Delors, Declaração de Hamburgo e Declaração Mundial sobre a Educação Superior para o Século XXI, entre outros).
\end{abstract}

Nesse sentido, a partir daqui, passamos a verificar a relação entre os três elementos anteriormente analisados (os quatro passos, o TWI e o sistema Toyota de produção) e os relatórios da Unesco para a educação mundial a partir de seus dois mais significativos documentos que irão pautar as bases orientadoras de políticas educacionais nos países centrais, bem como nos países em desenvolvimento: o relatório Faure de 1973 e o relatório Delors de 1996. Apesar de serem documentos produzidos em diferentes contextos, podemos compreender um encadeamento teórico-ideológico entre eles, considerando o relatório Delors et al. (2003) como a síntese de ambos a partir de seu conjunto de "quatro pilares" da educação para o século XXI:

Aprender a conhecer, isto é adquirir os instrumentos da compre-
ensão; aprender a fazer, para poder agir sobre o meio envolven-
te; aprender a viver juntos, a fim de participar e cooperar com os
outros em todas as atividades humanas; finalmente aprender a
ser, via essencial que integra as três precedentes. (DELORS et al.,
2003, p. 90; destaques do autor)

Como o relatório Faure (1973) centra-se principalmente no último elemento, o "aprender a ser”, acreditamos ser possível analisar a 
relação entre os documentos da Unesco e os três elementos anteriores, via relatório Delors et al. (2003). Para tanto, desenvolveu-se um quadro como forma de visualizar e comparar os elementos anteriores centrados nos "quatro passos" de Charles Allen e os princípios do TWI, com os "quatro pilares” da educação para o século XXI presentes no relatório Delors, conforme abaixo:

\section{QUADRO 2}

\section{COMPARAÇÃO ENTRE "OS QUATROS PASSOS”, O TWI E OS “QUATRO PILARES” DE DELORS}

\begin{tabular}{|c|c|}
\hline OS “QUATRO PASSOS” DE ALLEN E O TWI & OS QUATRO PILARES DE DELORS \\
\hline $\begin{array}{l}\text { Preparação/Apresentação/Métodos de Trabalho - MT: } \\
\text { o objetivo deste programa [MT] era ajudar os } \\
\text { supervisores a produzirem maiores quantidades de } \\
\text { produtos com qualidade em menos tempo, fazendo } \\
\text { o melhor uso da mão-de-obra, máquinas e material } \\
\text { disponível no momento (ALLEN, 1919). }\end{array}$ & $\begin{array}{l}\text { Aprender a conhecer: adquirir os instrumentos da } \\
\text { compreensão; é um "meio, porque se pretende que cada } \\
\text { um aprenda a compreender o mundo que o rodeia [...] } \\
\text { para desenvolver as suas capacidades profissionais, } \\
\text { para comunicar. Finalidade, porque seu fundamento é } \\
\text { o prazer de compreender, de conhecer, de descobrir" } \\
\text { (DELORS et al., 2003, p. 91). }\end{array}$ \\
\hline $\begin{array}{l}\text { Relações de Trabalho - RT: esse programa [RT] estava } \\
\text { fundamentado em desenvolver técnicas para melhoria } \\
\text { das relações entre supervisores e subordinados, ou seja, } \\
\text { as "relações de trabalho" deveriam ser orientadas para } \\
\text { melhorias nas relações sociais no ambiente produtivo. }\end{array}$ & $\begin{array}{l}\text { Aprender a viver juntos: a fim de participar e cooperar } \\
\text { com os outros em todas as atividades humanas. "O } \\
\text { confronto através do diálogo e da troca de argumentos } \\
\text { é um dos instrumentos indispensáveis à educação do } \\
\text { século XXI" (DELORS et al., 2003, p. 98). Dá-se por } \\
\text { intermédio do desenvolvimento de projetos comuns } \\
\text { que possibilitem o trabalho cooperado e minimizem as } \\
\text { tensões geradas a partir das diferenças individuais ou de } \\
\text { determinados grupos. }\end{array}$ \\
\hline $\begin{array}{l}\text { Aplicação/Instrução de Trabalho - IT: os objetivos } \\
\text { desse item estão fundamentados em dois pontos } \\
\text { principais: desde que o poder para aplicar uma coisa } \\
\text { é diferente de simplesmente conhecê-la, ele deve ser } \\
\text { treinado em aplicar de verdade ou colocar em prática } \\
\text { o que foi apresentado [...] para verificar o estágio de } \\
\text { conhecimento que o aluno entendeu em todos os pontos } \\
\text { da lição). O foco da IT era instruir operários mais do } \\
\text { que "deixá-los aprender" [...] Um ensino fraco pode } \\
\text { realmente limitar o aprendizado deles (ALLEN, 1919) }\end{array}$ & $\begin{array}{l}\text { Aprender a fazer: para poder agir sobre o meio } \\
\text { envolvente. Surge a questão: "como ensinar o aluno a } \\
\text { pôr em prática os seus conhecimentos e, também, como } \\
\text { adaptar a educação ao trabalho futuro quando não se } \\
\text { pode prever qual será a sua evolução?" (DELORS et al., } \\
\text { 2003, p. 93). }\end{array}$ \\
\hline $\begin{array}{l}\text { Teste/Programa de Desenvolvimento - PD: o programa } \\
\text { PD tinha por objetivo/fim descrever um problema de } \\
\text { produção, apresentar a possível solução, ou seja, verificar } \\
\text { empiricamente a efetividade das etapas anteriores. }\end{array}$ & $\begin{array}{l}\text { Aprender a ser: via essencial que integra as três } \\
\text { precedentes. Esse pilar é, de fato, a materialização da } \\
\text { inter-relação dos três pilares anteriores e deve orientar } \\
\text { a educação necessária a uma "nova sociedade" que se } \\
\text { desenha no século XXI, sendo que "esta perspectiva } \\
\text { deve, no futuro, inspirar e orientar as reformas } \\
\text { educativas, tanto em nível da elaboração de programas } \\
\text { como da definição de novas políticas pedagógicas" } \\
\text { (DELORS et al., 2003, p. 102). }\end{array}$ \\
\hline
\end{tabular}

Fonte: Elaboração do autor.

Nossa intenção ao estabelecermos um comparativo entre as aparentemente diferentes propostas para a formação profissional no ambiente produtivo e para a educação no espaço escolar é expor o encadeamento teórico-ideológico que perpassa a ambas: a relação imprescindível entre o trabalho e educação enquanto estrutura necessária para a constituição de um sujeito-trabalhador que necessita se apropriar de certos conhecimentos para o desempenho profissional, de modo a contribuir cada vez para a valorização do valor enquanto força de trabalho produtiva. Partindo da compreensão do encadeamento 
teórico-ideológico em questão, seguem abaixo as sínteses dos principais elementos que expusemos até então:

- Preparação/Apresentação/Aprender a conhecer: a "preparação" tem, em sua definição, o fato de haver uma necessidade de sensibilizar o trabalhador em formação para o ato de aprender e que, para tal intento, o conhecimento novo deve ser “ancorado” em um pré-existente, situação muito próxima, em termos conceituais, do que propõe o "aprender a conhecer”, que privilegia “o domínio dos próprios instrumentos do conhecimento” (DELORS et al., 2003, p. 90).

- Relações de trabalho/Aprender a viver juntos: a criação e implementação de um conjunto de técnicas e métodos que estimulem o convívio harmonioso entre e intra níveis hierárquicos, e o trabalho cooperado por meio de objetivos comuns previstos tanto para a produção como para a organização como um todo, proposta diretamente relacionada à pedagogia de projetos.

- Aplicação/Aprender a fazer: a necessidade de desenvolver um conjunto de habilidades e competências, tanto nos professores-instrutores quanto nos alunos-trabalhadores, como forma de suprir as necessidades de um novo paradigma produtivo.

- Teste/Aprender a ser: trata-se de sínteses dos itens anteriores, componentes de cada proposta de formação, previstas nos "quatro passos" e nos "quatro pilares", respectivamente.

\section{A RELAÇÃO ENTRE A FÓRMULA ALLEN-RICHARDS E O PAICA-OCDE}

O complexo de elementos historicamente encadeados e anteriormente apresentados, o qual compreende desde propostas metodológicas de caráter prático-utilitarista até valores universais válidos à educação do século XX e XXI, necessita de parâmetros objetivos mensuráveis, no intuito de verificar se a apropriação desse complexo teórico-ideológico vem ocorrendo nos diversos países que o incorporaram em suas políticas educacionais. Nesse sentido, em concomitância à criação dos elementos que darão suporte ideológico para as referidas políticas públicas, concebem-se os instrumentos necessários para a mensuração quantitativa do investimento em "capital humano" desses mesmos elementos a partir de uma lógica de eficiência econômica baseada em recursos financeiros.

Para confirmar a existência desses possíveis instrumentos de mensuração de capital humano, bem como de que forma esses instrumentos se relacionam com o complexo histórico teórico-ideológico acima apresentado, propomos, neste item, a análise de duas ferramentas aparentemente distintas concebidas em determinados contextos históricos e que, em nossa concepção materialista histórica, apresentam-se como complementares e imbricadas diretamente ao complexo 
teórico-ideológico anteriormente analisado: a Fórmula de Eficiência Allen-Richards e o Paica da OCDE.

Tanto nos documentos do referido programa quanto nas partes constituintes da fórmula de Allen-Richards, encontram-se elementos que ratificam a afirmação de que a educação, em última instância, deve ser exclusivamente voltada à formação de futuros trabalhadores com níveis específicos de qualificação profissional. Para tanto, cabe aos professores ensinar aos seus "aprendizes" o estritamente necessário para o desempenho apropriado à execução de tarefas no ambiente produtivo.

Além de desenvolver o método dos "quatro passos", posteriormente adaptado ao TWI e incorporado ao sistema Toyota de produção, Allen dedicou seus estudos à maximização do aprendizado, no intuito de avaliar o tempo e o nível de aprendizado dos alunos. Os estudos realizados por Charles Allen e Charles R. Richards resultaram na fórmula de eficiência Allen-Richards, baseada em cinco fatores que medem a eficiência profissional, onde o peso de cada fator componente varia conforme a categoria profissional, quais sejam: semiqualificado, qualificado, técnico ou engenheiro. Conforme documento do Senai (2012, p. 50), "Richards cria a fórmula $E=\mathrm{f}(\mathrm{M}, \mathrm{T}, \mathrm{I})$, que mais tarde é ampliada por Allen, incluindo (J) e (Mo)". Sendo assim, a fórmula Allen-Richards fica assim composta: $E=f(\mathrm{M}, \mathrm{T}, \mathrm{I}, \mathrm{J}, \mathrm{Mo})$. Cada item da fórmula é descrito da seguinte forma: $E$ - eficiência; $f$ - função; $M$ - habilidades manuais; $\mathrm{T}$ - conhecimentos técnicos essenciais; I - conhecimentos técnicos adicionais ou medianos; J - capacidade de julgamento; e Mo - fatores morais ou de motivação.

$\mathrm{Na}$ lógica desenvolvida pela fórmula Allen-Richards, o trabalhador considerado qualificado deve possuir todos os elementos que interferem na eficiência profissional, quais sejam: M, T, I, J e Mo. Já para um trabalhador semiqualificado, sobressaem os fatores relacionados a habilidades manuais (M) e conhecimentos técnicos essenciais (T). Segundo Senai (2012, p. 51), compreende-se que "para cada categoria profissional são atribuídos pesos diferenciados a cada um dos fatores”.

Já o Paica é considerado a avaliação internacional de maior envergadura e abrangência jamais realizada em matéria de competências do Ciclo 1 foram: Alemanha, Austrália, Áustria, Bélgica, Canadá, Coreia, Dinamarca, Espanha, Estados Unidos Estônia, Federação Russa Finlândia, França, Irlanda Itália, Japão, Noruega Países Baixos, Polônia, Reino Unido, República Checa República Eslovaca e Suécia. Já o Ciclo 2 foi composto por: Chile, Eslovênia Grécia, Indonésia, Israel, Lituânia, Nova Zelândia, Singapura e Turquia. de adultos (OCDE, 2013), sendo que o referido programa foi aplicado em diversos países através da criação de dois ciclos: o primeiro deles foi de 2008 a 2013 e o segundo teve seu início em 2012 e encerrou-se em 2016.5 O programa foi realizado por meio de entrevistas com 5.000 pessoas em cada país, entre 16 e 65 anos, tendo por objetivo central analisar as competências de leitura, escrita, aritmética, resolução de problemas e verificar como tais competências são utilizadas no trabalho. A intenção é que o Paica possa ser ampliado ao longo do tempo para outros países não previstos nos ciclos já aplicados, permitindo que "os decisores políticos analisem o desenvolvimento de aspectos fundamentais do capital 
humano nos seus respectivos países", bem como possibilitando uma melhor compreensão sobre as lacunas presentes entre "as necessidades dos mercados de trabalho e os sistemas de educação e formação” (OCDE, 2013, p. 1).

No que se refere ao Paica, a OCDE (2013) compreende que a distribuição de atividades de trabalhadores define o desenvolvimento de suas habilidades, ou seja, a qualificação do trabalho é concomitante à qualificação educacional. No tocante à questão da qualificação profissional, a OCDE compreende que há uma sobrequalificação, isto é, os trabalhadores possuem uma qualificação maior do que a exigida por seus postos de trabalho (são $21 \%$ dos trabalhadores). Já os subqualificados, que têm a qualificação menor do que a exigida pelos postos de trabalho, somam 13\% dos trabalhadores. Segundo os dados da OCDE (2013), os trabalhadores sobrequalificados se esforçam menos que os subqualificados, causando desperdício, enquanto os subqualificados se esforçam mais que os sobrequalificados, gerando stress. Torna-se propósito dos sistemas de educação a readequação dessas disparidades presentes no mercado de trabalho e, nesse caso, a melhor maneira de determinar a extensão do descompasso da qualificação profissional é medir o nível de escolaridade exigido no ambiente de trabalho.

Nota-se incialmente que os elementos de competência analisados no Paica - competências cognitivas (leitura, aritmética, alfabetização); interação e aptidões sociais (cooperação, colaboração); competências físicas (aptidões motrizes) e aptidões de aprendizagem - têm como base referencial a fórmula de Allen-Richards, na qual cada fator da fórmula pode ser relacionado com uma ou mais habilidades analisadas pelo Paica. A fórmula de Allen-Richards consiste em cinco elementos que resultam em um objetivo central, qual seja, a eficiência do trabalhador, a qual, por sua vez, corresponde aos resultados que esse mesmo trabalhador obtém através da utilização das habilidades analisadas pelo Paica. No quadro abaixo, demonstramos de forma comparativa as semelhanças entre as duas propostas: 


\begin{tabular}{|c|c|c|}
\hline FATORES & FÓRMULA DE ALLEN-RICHARDS & PAICA-OCDE \\
\hline$E$ & Eficiência do operário. & $\begin{array}{l}\text { Resultado do operário através da análise de suas } \\
\text { habilidades. }\end{array}$ \\
\hline M & $\begin{array}{l}\text { Habilidade manipulativa (cortar, limar, } \\
\text { desbastar, aplainar, furar, rebitar, soldar e serrar; } \\
\text { execução de tarefas e operações ensinadas em } \\
\text { oficinas; conhecimento de todos os processos } \\
\text { manuais diretamente relacionados às tarefas). }\end{array}$ & $\begin{array}{l}\text { Destreza (habilidade ou precisão com as mãos ou } \\
\text { os dedos); aprendizagem no trabalho (aprender } \\
\text { coisas novas a partir de supervisores ou colegas de } \\
\text { trabalho; aprender fazendo; manter-se atualizado } \\
\text { com os novos produtos ou serviços). }\end{array}$ \\
\hline $\mathrm{T}$ & $\begin{array}{l}\text { Conhecimentos técnicos essenciais } \\
\text { (conhecimentos necessários para a execução } \\
\text { das tarefas e operações que requeiram um } \\
\text { mínimo de raciocínio para sua aplicação; de } \\
\text { matemática, cálculo técnico e ciências, normas } \\
\text { essenciais de segurança industrial; terminologia } \\
\text { técnica referente às tarefas e operações). }\end{array}$ & $\begin{array}{l}\text { Matemática (o cálculo dos preços, custos } \\
\text { ou orçamentos; uso de frações, decimais ou } \\
\text { percentagens; uso de calculadoras; preparar } \\
\text { gráficos ou tabelas; álgebra ou fórmulas; uso da } \\
\text { matemática ou estatística avançada - cálculo, } \\
\text { trigonometria, regressões). }\end{array}$ \\
\hline I & $\begin{array}{l}\text { Conhecimentos técnicos adicionais } \\
\text { (conhecimentos tecnológicos adicionais que } \\
\text { possam melhorar a eficiência do operário ao } \\
\text { executar as tarefas e operações e mesmo } \\
\text { possibilitar uma fácil adaptação quando em face } \\
\text { de novas técnicas industriais; conhecimentos } \\
\text { correlatos de ciências, matemática, desenho } \\
\text { e linguagem; conhecimentos sobre normas } \\
\text { de segurança; conhecimentos que possam } \\
\text { melhorar a cultura). }\end{array}$ & $\begin{array}{l}\text { Leitura (leitura de documentos - instruções, cartas, } \\
\text { memorandos, e-mails, artigos, livros, manuais, } \\
\text { faturas, recibos, diagramas, mapas); escrita } \\
\text { (escrever documentos - cartas, memorandos, } \\
\text { e-mails, artigos, relatórios, formulários); matemática } \\
\text { (já citado acima); competências em tecnologias } \\
\text { das informação e comunicação - TIC, (usando } \\
\text { e-mail, internet, planilhas, processadores de } \\
\text { texto, linguagens de programação; condutor de } \\
\text { transações on-line; participar de discussões on-line } \\
\text { (conferências, chats)). }\end{array}$ \\
\hline J & $\begin{array}{l}\text { Capacidade de julgamento (conhecimentos } \\
\text { teóricos que permitem avaliar rapidamente } \\
\text { uma situação; aplicação de M, T, I a situações } \\
\text { novas dentro do trabalho; capacidade de } \\
\text { formar juízo crítico ou decidir sobre o caminho } \\
\text { a seguir diante de novas situações; capacidade } \\
\text { e rapidez para solucionar qualquer problema } \\
\text { ou situação de trabalho, prescindindo de } \\
\text { consulta a outras pessoas; faculdade de avaliar } \\
\text { pesos, distâncias, qualidade, eficiência, etc., } \\
\text { sem recorrer aos instrumentos adequados). }\end{array}$ & $\begin{array}{l}\text { Solução de problemas (enfrentando problemas } \\
\text { complexos (pelo menos } 30 \text { minutos de pensamento } \\
\text { para encontrar uma solução); descrição de tarefas } \\
\text { (escolher ou alterar a sequência de tarefas de } \\
\text { trabalho, a velocidade de trabalho, horas de } \\
\text { trabalho; escolher como fazer o trabalho). }\end{array}$ \\
\hline Mo & $\begin{array}{l}\text { Fatores de ordem moral e de motivação (atitude } \\
\text { para com os companheiros; honestidade; } \\
\text { disciplina; pontualidade; iniciativa no } \\
\text { desempenho das suas funções; outros fatores } \\
\text { que afetam condições ou atitudes de trabalho), }\end{array}$ & $\begin{array}{l}\text { Habilidades cooperativas (cooperacional ou } \\
\text { colaborando com os colegas de trabalho); } \\
\text { habilidades de auto-organização (organizar o seu } \\
\text { tempo). }\end{array}$ \\
\hline
\end{tabular}

Fonte: Elaboração do autor.

$\mathrm{O}$ "M" é referente à habilidade manipulativa que, na fórmula, representa a maestria de cortar, limar, desbastar, aplainar, furar, rebitar, soldar e serrar, assim como a execução de tarefas e operações que são ensinadas em oficinas e o conhecimento de todos os processos manuais, desde que estejam diretamente relacionados às tarefas (SENAI, 2012). Podemos associar essa habilidade a duas outras apresentadas pelo Paica, sendo a primeira a destreza, que denota a precisão que o operário tem para a utilização das mãos e dos dedos (habilidades manuais), de forma que contribua para o seu serviço; e a segunda, a aprendizagem no trabalho, que é quando o trabalhador obtém aprendizado a partir do auxílio de supervisores ou colegas de empresa, assim como aprende através da prática ou mantendo-se atualizado com relação aos novos produtos ou serviços (OCDE, 2013). 
Na fórmula de Allen-Richards, o "T" é o fator dos conhecimentos técnicos essenciais, sendo os conhecimentos necessários para a execução das tarefas e operações que exigem ao menos o mínimo de raciocínio para a sua aplicação: conhecimentos de matemática, cálculo técnico e ciências, das normas essenciais de segurança industrial e da terminologia técnica referente às tarefas e operações. Esse elemento se expressa nos conhecimentos matemáticos encontrados no Paica, que se referem ao cálculo dos preços, custos ou orçamentos, ao uso de frações, decimais, porcentagens ou calculadoras, à preparação de gráficos ou tabelas, álgebra ou fórmulas, ao uso da matemática ou estatística avançada, como cálculo, trigonometria e regressões.

Os conhecimentos técnicos adicionais correspondem ao fator "I". Eles são os saberes tecnológicos adicionais que podem melhorar a eficiência do trabalhador ao executar as tarefas e operações e até mesmo possibilitar uma fácil adaptação quando em face de novas técnicas industriais: os conhecimentos correlatos de ciências, matemática, desenho e linguagem; e os conhecimentos sobre normas de segurança e que possam melhorar a cultura. Tais técnicas condizem com as habilidades de leitura que, conforme o Paica, correspondem à leitura e à escrita de documentos (instruções, cartas, memorandos, e-mails, artigos, livros, manuais, faturas, recibos, diagramas, mapas, relatórios e formulários). O fator "I" ainda remete ao conhecimento da matemática - já explicado anteriormente - e das competências em TIC, que abordam a utilização de e-mail, internet, planilhas, processadores de textos, linguagens de programação, tal como a condução de transações e a participação de discussões (conferências e chats) on-line (OCDE, 2013).

Ainda consta na fórmula a capacidade de julgamento, que é representada pelo elemento "J" e refere-se aos conhecimentos técnicos que permitem avaliar rapidamente uma situação, quais sejam: a aplicação de "M", “T”, "I” às novas situações dentro do trabalho; a capacidade de formar juízo crítico ou decidir sobre o caminho a seguir diante de novas situações; a capacidade e rapidez para solucionar qualquer problema ou situação de trabalho, prescindindo de consulta às outras pessoas; a faculdade de avaliar pesos, distâncias, qualidade, eficiência, etc., sem recorrer aos instrumentos adequados (SENAI, 2012). É possível associar tal elemento a, pelo menos, três habilidades citadas no Paica: 1) conhecimentos matemáticos - que já foram citados anteriormente; 2) solução de problemas - enfrentar problemas complexos, tendo, pelo menos, trinta minutos de pensamento para encontrar uma solução; e 3) descrição de tarefas - escolher ou alterar a sequência de tarefas de trabalho, a velocidade e horas de trabalho, assim como escolher como fazer o trabalho.

O último fator apresentado e constado na fórmula Allen-Richards é o "Mo", que representa os fatores de ordem moral e de motivação, 
sendo: as atitudes do trabalhador para com os colegas; a honestidade, a disciplina, a pontualidade; a iniciativa no desempenho das funções e os outros fatores que afetam condições ou atitudes de trabalho. Esse fator se equipara às habilidades comparativas, que, segundo o Paica, são o ato cooperacional ou colaborativo com os colegas de trabalho, assim como as habilidades de auto-organização como, por exemplo, a organização de seu tempo.

Dentre as possíveis categorizações dos trabalhadores, de acordo com a fórmula de Allen-Richards, há os semiqualificados, os qualificados e os altamente qualificados, que variam conforme possuam dois ou mais elementos da fórmula em proporção conveniente. O Paica também afirma tal categorização, porém dividindo-a somente em subqualificados e sobrequalificados, indicando que o ideal de trabalhador qualificado deve ser buscado por meio de educação e qualificação profissional adequada ao molde das demandas do mercado de trabalho nos diversos contextos socioculturais nos mais variados países.

\section{CONSIDERAÇÕES FINAIS}

Como considerar uma educação reduzida à mera adequação aos níveis de qualificação profissional, em mundo cada vez mais permeado pela superfluidez do trabalho (JAPPE, 2013), em que um quantum cada vez maior de trabalho é “dispensado" por conta do desenvolvimento das forças produtivas do capital? Nesse sentido, por que ainda insistir em uma formação que não privilegia o desenvolvimento omnilateral do ser humano se uma suposta "educação para o trabalho" não dá mais conta de mitigar as contradições presentes na relação entre capital e trabalho? Chegamos até o presente estágio de nossa análise apresentando essas duas questões que, a nosso ver, permeiam todo o debate que se estabelece principalmente no momento atual.

Ao determinarmos as relações históricas entre elementos aparentemente distintos provenientes do embate entre capital e trabalho no modo de produção capitalista, presentes desde o início do século XX até o recente século XXI, pretendemos demonstrar que, apesar do avanço da ciência e da tecnologia, em termos de produção do conhecimento, o modo de produção capitalista recorre constantemente a velhos instrumentos, no intuito de solucionar novos problemas, nesse caso, a educação voltada para o trabalho. Na essência do Programa para a Avaliação Internacional das Competências dos Adultos, concebido em pleno século XXI, encontramos desde os preceitos dos métodos dos "quatro passos" e TWI aos rudimentos da fórmula para a eficiência de Allen-Richards, demonstrando que o ser social, o ser humano, ainda permanece sendo concebido e formado como mero capital humano, uma mercadoria com vida útil pré-determinada em termos de permanência no plano da "população 
economicamente ativa". Nesse sentido, a educação tem como papel fundamental adequar a força de trabalho a níveis de produtividade que sejam úteis a determinados contingentes de profissões necessárias ao pleno desenvolvimento do modo de produção capitalista.

Como afirma Laval (2004, p. xix), os

\section{[...] objetivos que se podem dizer 'clássicos' de emancipação polí- tica e de expansão pessoal que estavam fixados para a instituição escolar são substituídos pelos imperativos prioritários de eficácia produtiva e de inserção profissional.}

Se o horizonte previsto, em termos de formação humana, para a educação no século XXI continua sendo a produção e o nivelamento de sujeitos trabalhadores semiqualificados, qualificados ou altamente qualificados, não considerando a possibilidade de ampliação das capacidades intelectuais científicas, tecnológicas e artísticas da ampla população, então vislumbramos somente a perpetuação do modo de produção capitalista, bem como o aumento dos níveis de valorização de valor. Concordamos com Jappe (2013, p. 12) quando afirma que o

\section{[...] trabalho baseado na ideologia de resultados, na otimização do tempo e na superação de si diz respeito às mudanças advindas do "novo espírito do capitalismo" que promoveu as transformações na organização da família, do trabalho e da propriedade - preca- rização da vida familiar, fim da propriedade durável em virtude do nomadismo urbano e rural, proliferação do trabalho temporário.}

As alterações advindas do "novo espírito do capitalismo" verificado a partir da constituição de novos indivíduos atomizados pela busca da ideologia do "sujeito neoliberal" (LAVAL; DARDOT, 2016) e do “autogestor de si” (BRÖCKLING, 2016), reafirmam os limites impostos à educação atual como mera depositária da formação desse novo sujeito adequado ao quadro de incertezas e precarização provenientes do estágio de desenvolvimento socioeconômico proporcionado pelo capital.

\section{REFERÊNCIAS}

ALLEN, Charles R. The instructor, the man and the job: A hand book for instructors of industrial and vocational subjects. Philadelphia: Lippincott, 1919.

BRÖCKLING, Ulrich. The entrepreneurial self: Fabricating a new type of subject. London: Sage, 2016. 
HUTZINGER, Jim. As raízes do Lean. 2005. Disponível em: <http://www.lean.org.br/artigos/97/asraizes-do-lean.aspx>. Acesso em: 15 jan. 2016.

JAPPE, Anselm. A decomposição do capitalismo e de suas críticas. São Paulo: Hedra, 2013.

LAVAL, Christian. A escola não é uma empresa: o neoliberalismo em ataque ao ensino público. Londrina: Planta, 2004.

LAVAL, Christian; DARDOT, Pierre. A nova razão do mundo: ensaio sobre a sociedade neoliberal. São Paulo: Boitempo, 2016.

MANACORDA, Mario Alighiero. Marx e a pedagogia moderna. São Paulo: Alínea, 2007.

MARI, Cezar Luiz de; GRADE, Marlene. Reformas da educação superior: banco mundial, conhecimento e consensos ativos. Educação em Perspectiva, Viçosa, v. 1, n. 2, p. 65-79, 2011.

MORGADO, Suzana Pinguello; LARA, Ângela Mara de Barros. Estudo e Diagnóstico da Unesco: serviços e atendimento para crianças de 0 a 6 anos no Brasil. Revista Eletrônica de Educação, Londrina, Ano IV, n. 8, p. 1-12, jan./jul. 2011.

MUELLER, Rafael Rodrigo. Tecnologias gerenciais, educação e capital. Revista Brasileira de Educação, Rio de Janeiro, v. 18, n. 54, p. 739-760, set. 2013. Disponível em: <http://www.scielo. br/scielo.php?script=sci_arttext\&pid=S1413-4782013000300012\&lng=pt\&nrm=iso > . Acesso em: 28 fev. 2016.

ORGANIZAÇÃO PARA A COOPERAÇÃO E DESENVOLVIMENTO ECONÔMICO - OCDE. Perspectivas da OCDE sobre as Competências para 2013: primeiros resultados do estudo sobre as competências de adultos. São Paulo: Fundação Santillana, 2014. Disponível em: <http://www. moderna.com.br/lumis/portal/file/fileDownload.jsp?fileId=8A8A8A8246D8770E0146DEB4A9AE 413D>. Acesso em: 20 abr. 2015

RODRIGUES, Marilda Merência. A noção de Educação ao longo da vida como eixo orientador das políticas de educação para jovens e adultos. Cadernos ANPAE, Florianópolis, v. 8, p. 1-18, 2009. Disponível em: <http://www.gepeto.ced.ufsc.br/index.php/artigos/viewdownload/21artigos/102-a-nocao-de-educacao-ao-longo-da-vida-como-eixo-orientador-das-politicas-deeducacao-para-jovens-e-adultos.html>. Acesso em: 15 abr. 2015.

SCHULTZ, Theodore W. O capital humano: investimentos em educação e pesquisa. Rio de Janeiro: Zahar, 1971.

SHIROMA, Eneida O. Sentidos da descentralização nas propostas internacionais para a educação. In: BORGES, Liliam Faria Porto; MAZZUCO, Neiva Gallina (Org.). Democracia e políticas sociais na América Latina. São Paulo: Xamã, 2009. v. 1000, p. 179-192.

SISTEMA NACIONAL DE APRENDIZAGEM INDUSTRIAL - SENAI. Série metódica ocupacional (SMO): o ensino profissional para o aprender fazendo. São Paulo: Senai-SP, 2012. 160 p. (Engenharia da Formação Profissional).

WERTHEIN, Jorge. Fundamentos da nova educação. Brasília: Unesco, 2000.

\author{
RAFAEL RODRIGO MUELLER \\ Universidade do Extremo Sul Catarinense - Unesc -, Criciúma, Santa Catarina, \\ Brasil \\ rrmueller@unesc.net
}

